\title{
PERFORMANCE PREDICTIONS OF AIR-COOLED CONDENSERS HAVING CIRCULAR AND ELLIPTIC CROSS-SECTIONS WITH ARTIFICIAL NEURAL NETWORKS
}

\author{
F. Selimefendigil1,*, H. F. Öztop ${ }^{2}$
}

\begin{abstract}
In this study, mathematical models of air cooled condensers with circular and elliptic cross-sections were developed and performances were evaluated with artificial neural networks. Air velocity, orientation angle and ambient temperature were used as the input to the neural network structure while heat transfer rate to the air was used as the output. The data sets were generated from high fidelity, computationally inefficient expensive three dimensional computational fluid dynamics simulations. It was observed that artificial neural network model replaces computational fluid dynamics model and based on the mathematical model with artificial neural network, elliptic condensers perform better in terms of heat transfer compared to circular ones.
\end{abstract}

\section{Keywords: Refrigeration, Elliptic, Computational Fluid Dynamics, Artificial Neural Network}

\section{INTRODUCTION}

Energy efficiency and power consumption are important concepts in engineering systems along with the environmental issues and cost of production. Therefore, a huge amount of literature is dedicated to this topic in power generation and refrigeration applications. Numerical and experimental studies were conducted on the design and performance of condenser of a household refrigerator which is a wire on tube heat exchanger [1-7]. In order to enhance the heat transfer on the air side, the wires were added on the refrigerant pipe. A mathematical derivation for the hot wall condensers used in domestic refrigerators was made by [8] and correlations were developed to estimate the heat transfer performance for the air side of the condenser. A dimensionless correlation for a wire and tube condenser in natural convection conditions was developed by [6] with the experimental data. Different tube outer diameters, number of wire pairs and number of tube rows were used in the experimental study. Numerical, experimental and optimization study for geometrical parameters of a wire-and-tube condensers used in domestic refrigerator was conducted by [9] and 6\% reduction in condenser weight is achieved. The heat transfer performance may be affected by changing the cross-sectional shape of the condensers. In heat transfer applications, surface corrugations are added to enhance the heat transfer performance [10-14]. Condensers having elliptic crosssectional shapes have different heat transfer characteristics as compared to the circular shapes. An experimental study of heat transfer performance and entropy generation for elliptic tubes with longitudinal fins was conducted by [15] and it was shown that fin location on the elliptic tube has significant effects on the heat transfer performance. [16] experimentally studied the free convection of air around an elliptic surface with constant heat flux. Correlations for the averaged hat transfer rate were obtained for various Rayleigh numbers and tube inclination angles. Artificial Neural Networks (ANN) have been extensively used to predict lumped performance parameters and to develop mathematical models for energy systems. In heat transfer applications, flow and thermal variables in every location of the system is not of interest in general, but average values are important. ANN is an effective tool to develop correlations for the desired input-out relations by using the experimental or numerical simulation data [17-22]. ANNs have been extensively used in energy related systems for modeling and predictions purposes as reviewed in [23]. The applications of artificial neural networks for thermodynamic analysis in refrigeration, air conditioning and heat pump systems were reviewed in [23] and it was concluded that the ANNS could be successfully applied for performance estimation in those systems. [24] used ANNs for performance analysis of vapor-compression system using various refrigerants. [25] applied ANN and adaptive neuro-fuzzy inference system methods for the experimental data obtained from evaporative condenser. It was shown that both ANN and ANFIS models gave prediction performances. In this study, ANN technique was used to obtain mathematical models for the air side heat transfer performances of circular and elliptic condensers. These models can be easily incorporated into a refrigeration system to make performance predictions in terms of ANN coefficients, velocity and temperature of air and orientation angle of the incoming air. 


\section{PHYSICAL MODEL AND MATHEMATICAL FORMULATION}

The schematic representation of the physical model along with the boundary conditions is shown in Figure 1. It is a model of an air cooled condenser with the geometrical parameters given in Table 1 . The tube surface and the wires were kept at constant temperature with non-slip boundary condition. The surface areas of the circular and elliptic condenser are assumed to be the same. Circular cylinders has radius of $r$, an elliptic configuration of has radius of $2 \mathrm{r}$ and $\mathrm{r} / 2$ in the major and minor axis. There are 8 cylinders per row. The gravity acts in negative $y$-direction and thermo- physical properties of the air were assumed to be temperature independent. The flow was assumed to be three dimensional and laminar and the variation in the density was modeled by using Boussinesq approximation which adds an additional term in the $\mathrm{y}$ - momentum equation.

Table 1. Geometrical parameters

\begin{tabular}{|l|c|}
\hline Property & Value \\
\hline Tube outer diameter $(\mathrm{mm})$ & 4.76 \\
\hline Tube pitch $(\mathrm{mm})$ & 20 \\
\hline Tube length $(\mathrm{mm})$ & 334 \\
\hline Tube rows & 8 \\
\hline Wire diameter $(\mathrm{mm})$ & 1.2 \\
\hline Number of wires per side & 47 \\
\hline Wire pitch $(\mathrm{mm})$ & 4.8 \\
\hline Height $(\mathrm{mm})$ & 275 \\
\hline
\end{tabular}

Conservation equation of mass, momentum and energy in a three dimensional Cartesian coordinate system for a laminar flow in 3D can be written in dimensional form as follows [26], [27]:

$$
\begin{gathered}
\frac{\partial u}{\partial x}+\frac{\partial v}{\partial y}+\frac{\partial w}{\partial z}=0 \\
u \frac{\partial u}{\partial x}+v \frac{\partial u}{\partial y}+w \frac{\partial u}{\partial z}=-\frac{1}{\rho} \frac{\partial p}{\partial x}+v\left(\frac{\partial^{2} u}{\partial x^{2}}+\frac{\partial^{2} u}{\partial y^{2}}+\frac{\partial^{2} u}{\partial z^{2}}\right) \\
u \frac{\partial v}{\partial x}+v \frac{\partial v}{\partial y}+w \frac{\partial v}{\partial z}=-\frac{1}{\rho} \frac{\partial p}{\partial y}+v\left(\frac{\partial^{2} v}{\partial x^{2}}+\frac{\partial^{2} v}{\partial y^{2}}+\frac{\partial^{2} v}{\partial z^{2}}\right)+\beta g\left(T-T_{c}\right) \\
u \frac{\partial w}{\partial x}+v \frac{\partial w}{\partial y}+w \frac{\partial w}{\partial z}=-\frac{1}{\rho} \frac{\partial p}{\partial z}+v\left(\frac{\partial^{2} w}{\partial x^{2}}+\frac{\partial^{2} w}{\partial y^{2}}+\frac{\partial^{2} w}{\partial z^{2}}\right) \\
u \frac{\partial T}{\partial x}+v \frac{\partial T}{\partial y}+w \frac{\partial T}{\partial z}=\alpha\left(\frac{\partial^{2} T}{\partial x^{2}}+\frac{\partial^{2} T}{\partial y^{2}}+\frac{\partial^{2} T}{\partial z^{2}}\right)
\end{gathered}
$$

Velocity is unidirectional and uniform and temperature is constant at the inlet for the incoming air. On the walls, no-slip boundary conditions with constant wall temperature are used. On the tube surface and wire, constant hot temperature with no-slip boundary condition was utilized. At the outlet, pressure outlet boundary condition was imposed. The governing equations along with the boundary conditions were solved by using the finite-volume method. The convective terms in the momentum and energy equations are solved using the QUICK scheme and the SIMPLE algorithm is used for velocity-pressure coupling. The resulting system of algebraic equations was solved using the Gauss-Seidel point-by-point iterative method and algebraic multigrid method.

\section{MATHEMATICAL MODEL WITH ANN}

ANNs are very promising in the approximation of complicated input-input relations and for approximating any nonlinearity up to a specified degree of accuracy [28], [29]. They are composed of neurons which are connecting processing elements and artificial neural network structure is composed of different layers; 
input, hidden and output layers. The nodes in the hidden layer perform input-output transformations by utilizing various activation functions, e.g., sigmoid, tangent hyperbolic. The weights of the ANN can be adjusted in order to minimize the difference between the outputs of numerical or experimental study and outputs of the neural network for a given topology. The main steps in the modeling are: data collection from numerical simulation as the input-output to the network, choosing the network architecture, determining the number of neurons, number of hidden layers, activation function and learning algorithm. The model then should be validated for the data set that were not used in the estimation.

The output parameters were determined by using the logistic sigmoid function which is defined as:

$$
f_{n}=\frac{1}{1+e^{-g_{n}}}
$$

where $g_{n}$ is defined as:

$$
g_{n}=\sum_{k=1}^{N} u_{k} W_{k n}+b_{k}
$$

where $u, W, N$ and $b$ denote the input parameter, weight, number of hidden neurons and bias term, respectively. are used

Among various performance parameters, mean square error (MSE) and coefficient of determination $\left(\mathrm{R}^{2}\right)$

widely. They are given as:

$$
\begin{aligned}
M S E & =\frac{1}{N} \sum_{k=1}^{N}\left(y_{k}^{N N}-y_{k}\right)^{2} \\
R^{2} & =1-\frac{\sum_{k=1}^{N}\left(y_{k}^{N N}-y_{k}\right)^{2}}{\sum_{k=1}^{N}\left(y_{k}-\bar{y}_{k}\right)^{2}}
\end{aligned}
$$

where $\mathrm{y}^{\mathrm{NN}}, \mathrm{y}, \mathrm{N}$ and $\mathrm{y}$ represent estimated value, simulation data, number of samples and the mean value of simulation data, respectively.

\section{RESULTS AND DISCUSSION}

The aim was to derive mathematical expressions for the heat transfer rate from the air-cooled condenser of circular and elliptic cross-sections with artificial neural networks by using the data set generated from a numerical simulation. The main parameters are velocity, orientation angle of the incoming velocity and ambient temperature. The minimum and maximum of these parameters are given in Table 2. 5 different velocities, 4 different temperatures and 5 different orientation angels and in total 100 different data sets generated from high fidelity computational fluid dynamics simulation was provided to the neural network structure as input data. The heat transfer rate from the condenser to the air was used as the output to the neural network. Thermodynamic analysis will be performed by using the obtained model of condenser form artificial neural networks. MATLAB (2010a) Neural Network Toolbox was utilized to select the number of hidden layers, number of neurons in each layer, training algorithm and approximating function. Feed-forward network structure with one hidden layer and linear output layer was selected. The number of the neurons of ANN model 15 for circular cross-sectional condenser and 20 for elliptic cross-sectional condenser. Tangent hyperbolic sigmoid function was used as the activation function in the ANN modeling. Random data division property of MATLAB is used to select the samples for training (75 samples), validation (15 samples) and test data (15 samples).

Table 3 and Table 4 demonstrate the number of samples for training, validation and testing. Network performances are represented in terms of mean squared error (MSE) values and regression R values for circular and elliptic condensers in the same table. $\mathrm{R}^{2}$ values which are closer to 1 indicates a good fit between the numerical output data and ANN output data. 
Table 2. Main Parameters

\begin{tabular}{|c|c|c|}
\hline Property & $\min$ & $\max$ \\
\hline Velocity $(\mathrm{u},(\mathrm{m} / \mathrm{s}))$ & 0.25 & 1.5 \\
\hline Orientation angle $(\mathrm{deg})$ & 0 & 60 \\
\hline Ambient temperature $\left({ }^{\circ} \mathrm{C}\right)$ & 10 & 40 \\
\hline
\end{tabular}

Table 3. Number of samples, mean squared error and regression values for various sets

\begin{tabular}{|c|ccc|c|}
\hline & \multicolumn{2}{|c|}{ Samples } & MSE & R \\
\hline Training & 70 & $4.653 \times 10^{-4}$ & 0.999 \\
\hline Validation & 15 & $2.935 \times 10^{-2}$ & 0.995 \\
\hline Training & \multicolumn{2}{|c|}{15} & $4.108 \times 10^{-2}$ & 0.997 \\
\hline Elliptic & \multicolumn{2}{|c|}{ Samples $\quad$ MSE } & R \\
\hline Training & 70 & $1.831 \times 10^{-4}$ & 0.999 \\
\hline Validation & 15 & $2.437 \times 10^{-2}$ & 0.996 \\
\hline Training & 15 & $1.383 \times 10^{-2}$ & 0.999 \\
\hline
\end{tabular}

Performance plot of the ANN model for circular condenser is shown in Figure 2 and as the number of epochs is increased, MSE becomes minimum. The best performance was attained at the 22th epoch. Regression plots and $\mathrm{R}$ values for training, validation, testing and for the whole group of samples for the circular and elliptic condenser are shown in Figure 3 and Figure 4. It represents the correlation between output and target data and the $\mathrm{R}$ values of results approaches to 1 . The outputs between the computational fluid dynamics simulation and artificial neural network model outputs for various values of air velocity, orientation angle and ambient temperature are represented in Table 4 for circular condenser and in Table 5 for elliptic condenser. In most case, the differences in the percentage are less than $6 \%$ and in all cases it remains below $6.5 \%$. By adjusting the number of neurons, number of hidden layers and by using different training algorithm this difference can be controlled. It is also possible, to introduce more data sets from high fidelity CFD computations when obtaining ANN model which will decrease the difference between the CFD and ANN predictions. It was shown that ANN can predict the heat transfer rate for the air side of the air-cooled condenser very efficiently. It can be used instead of a full high fidelity computational fluid dynamics model. As compared to the three dimensional computational fluid dynamics simulation model, mathematical model with ANN is compact and cheap. It can be directly incorporated into a thermodynamic model of a refrigeration system using this type of condenser and further performance evaluations can be made. Figure 5 demonstrates the effects of air velocity on the heat transfer for various ambient temperatures both for cylindrical and elliptic condenser. The results are obtained from artificial neural network mathematical model. As the velocity of incoming air increases, heat transfer rate enhances which is an expected result. This effect is more pronounced for the lower ambient temperatures. Elliptic condensers perform better heat transfer characteristics compared to circular ones especially in the lower ambient temperatures. Figure 6 depicts the influence of ambient temperature and orientation angle of the incoming air velocity for circular and elliptic condenser. As the ambient temperature decreases, heat transfer rate deteriorates for both cylindrical and elliptic condensers. The cooling capacity of the refrigerator is known to increase as the ambient temperature increases. As the orientation angle of the circular and elliptic condensers decreases, thermal performance deteriorates. The discrepancy between circular and elliptic condensers for various orientation angle is higher for lower ambient temperature when the heat transfer rate is higher. 
Table 4. Comparison of numerical simulation results with artificial neural network testing results for condensers with circular cross-section

\begin{tabular}{|c|c|c|c|c|c|}
\hline $\mathrm{v}(\mathrm{m} / \mathrm{s})$ & $\mathrm{T}\left({ }^{\circ} \mathrm{C}\right)$ & $\alpha\left({ }^{\circ}\right)$ & Q & QNN & Diff (\%) \\
\hline 0.25 & 10 & 0 & 2.517 & 2.5389 & -0.86844 \\
\hline 1.5 & 10 & 0 & 8.646 & 7.895 & 5.6858 \\
\hline 1 & 20 & 0 & 4.939 & 4.9156 & 0.47477 \\
\hline 0.75 & 30 & 0 & 2.681 & 2.6869 & -0.21943 \\
\hline 0.5 & 40 & 0 & 1.006 & 0.9768 & 2.9025 \\
\hline 0.25 & 10 & 15 & 2.518 & 2.4018 & 4.6141 \\
\hline 1.5 & 10 & 15 & 8.155 & 8.1509 & 0.050863 \\
\hline 1 & 20 & 15 & 4.638 & 4.651 & -0.28001 \\
\hline 0.75 & 30 & 15 & 2.52 & 2.5486 & -1.1365 \\
\hline 0.5 & 40 & 15 & 0.947 & 0.98633 & -4.153 \\
\hline 0.25 & 10 & 30 & 2.517 & 2.3262 & 5.5796 \\
\hline 1.5 & 10 & 30 & 7.671 & 7.6761 & -0.066296 \\
\hline 1 & 20 & 30 & 4.348 & 4.1288 & 5.0415 \\
\hline 1.5 & 20 & 30 & 5.739 & 5.706 & 0.57548 \\
\hline 0.75 & 30 & 30 & 2.357 & 2.3522 & 0.20453 \\
\hline 0.25 & 40 & 30 & 0.557 & 0.52506 & 5.7335 \\
\hline 1 & 40 & 30 & 1.441 & 1.4237 & 1.1998 \\
\hline 0.5 & 10 & 45 & 3.015 & 3.0222 & -0.2396 \\
\hline 1.5 & 10 & 45 & 6.55 & 6.4777 & 1.1042 \\
\hline 0.75 & 20 & 45 & 3.004 & 3.0038 & 0.0065733 \\
\hline 0.25 & 30 & 45 & 0.967 & 0.94008 & 2.7839 \\
\hline 1 & 30 & 45 & 2.455 & 2.4575 & -0.10019 \\
\hline 0.5 & 40 & 45 & 0.752 & 0.75801 & -0.79909 \\
\hline 1.5 & 40 & 45 & 1.631 & 1.7029 & -4.4103 \\
\hline 1 & 10 & 60 & 3.88 & 3.8435 & 0.94099 \\
\hline 0.75 & 20 & 60 & 2.368 & 2.4054 & -1.5782 \\
\hline 0.5 & 30 & 60 & 1.193 & 1.2514 & -4.8917 \\
\hline 0.25 & 40 & 60 & 0.38 & 0.35956 & 5.3801 \\
\hline
\end{tabular}

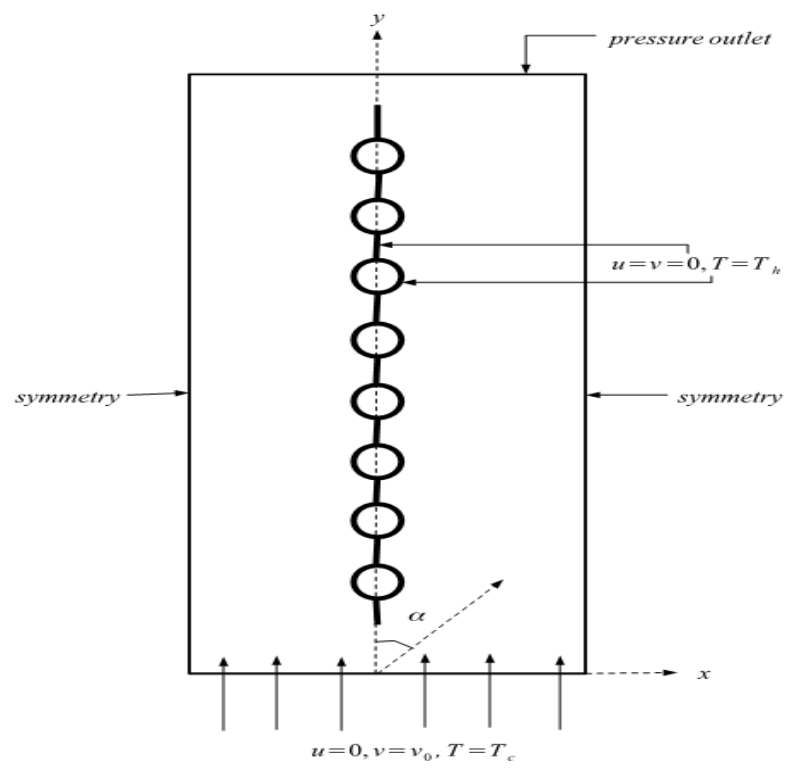

Figure 1. Schematic description of the geometry with boundary conditions

Table 5. Comparison of numerical simulation results with artificial neural network testing results for condensers with elliptic cross-section 
Journal of Thermal Engineering, Technical Note, Vol. 5, No. 3, pp. 105-114, April, 2019

\begin{tabular}{|c|c|c|c|c|c|}
\hline $\mathrm{v}(\mathrm{m} / \mathrm{s})$ & $\mathrm{T}\left(^{0} \mathrm{C}\right)$ & $\alpha\left(^{(}\right)$ & $\mathrm{Q}$ & $\mathrm{Q} N$ & Diff $(\%)$ \\
\hline 0.25 & 10 & 0 & 2.76 & 2.7749 & -0.53838 \\
\hline 1.5 & 10 & 0 & 9.246 & 9.2302 & 0.17102 \\
\hline 1 & 20 & 0 & 5.209 & 5.2944 & -1.6389 \\
\hline 0.75 & 30 & 0 & 2.829 & 2.8234 & 0.19686 \\
\hline 0.5 & 40 & 0 & 1.009 & 1.0069 & 0.21192 \\
\hline 0.25 & 10 & 15 & 2.76 & 2.7697 & -0.34969 \\
\hline 1.5 & 10 & 15 & 9.43 & 9.2946 & 1.4359 \\
\hline 1 & 20 & 15 & 5.51 & 5.5005 & 0.17173 \\
\hline 0.75 & 30 & 15 & 2.971 & 3.0266 & -1.8709 \\
\hline 0.5 & 40 & 15 & 1.127 & 1.0203 & 6.4679 \\
\hline 0.25 & 10 & 30 & 2.488 & 2.5011 & -0.52479 \\
\hline 1.5 & 10 & 30 & 7.156 & 7.1941 & -0.53228 \\
\hline 1 & 20 & 30 & 4.556 & 4.5464 & 0.21052 \\
\hline 1.5 & 20 & 30 & 5.368 & 5.3683 & -0.0059809 \\
\hline 0.75 & 30 & 30 & 2.492 & 2.5196 & -1.1059 \\
\hline 0.25 & 40 & 30 & 0.621 & 0.62757 & -1.0584 \\
\hline 1 & 40 & 30 & 1.504 & 1.5084 & -0.29382 \\
\hline 0.5 & 10 & 45 & 3.499 & 3.5012 & -0.061889 \\
\hline 1.5 & 10 & 45 & 7.061 & 6.9809 & 1.1337 \\
\hline 0.75 & 20 & 45 & 3.5108 & 3.5308 & -0.56941 \\
\hline 0.25 & 30 & 45 & 1.067 & 1.1167 & -4.6561 \\
\hline 1 & 30 & 45 & 2.938 & 2.9282 & 0.33225 \\
\hline 0.5 & 40 & 45 & 0.875 & 0.89174 & -1.9128 \\
\hline 1.5 & 40 & 45 & 1.761 & 2.0177 & -5.575 \\
\hline 1 & 10 & 60 & 4.384 & 4.3918 & -0.17748 \\
\hline 0.75 & 20 & 60 & 2.806 & 2.8153 & -0.33058 \\
\hline 0.5 & 30 & 60 & 1.425 & 1.4009 & 1.6899 \\
\hline 0.25 & 40 & 60 & 0.406 & 0.43108 & -6.1776 \\
\hline
\end{tabular}

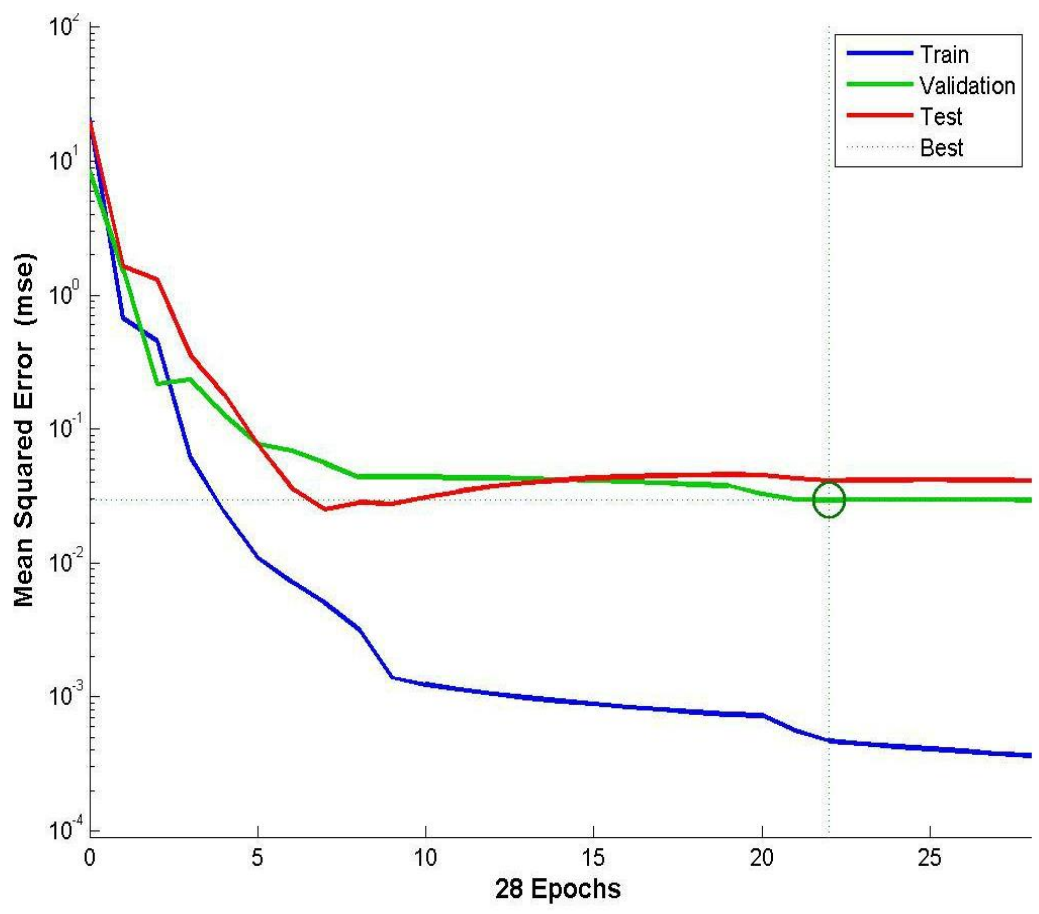

Figure 2. Performance plot for circular cross-section 

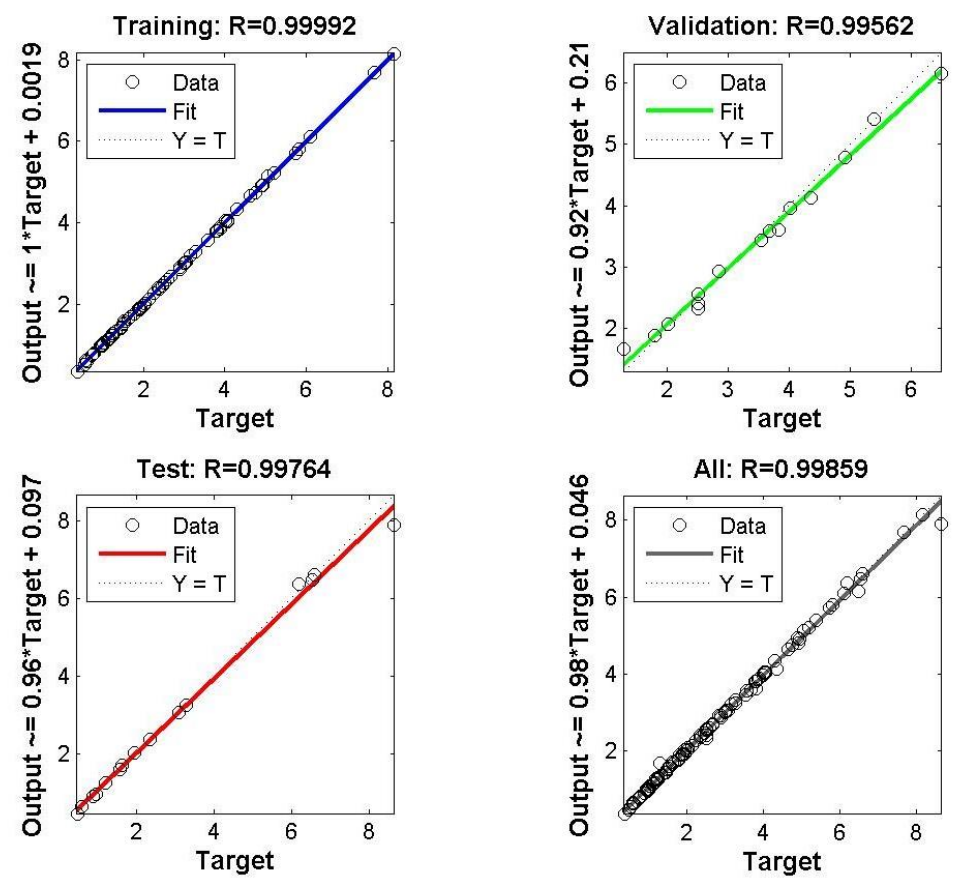

Figure 3. The regression plots of artificial neural network predictions and the numerical simulation results of circular cross-section for training, validation, test and combined set.
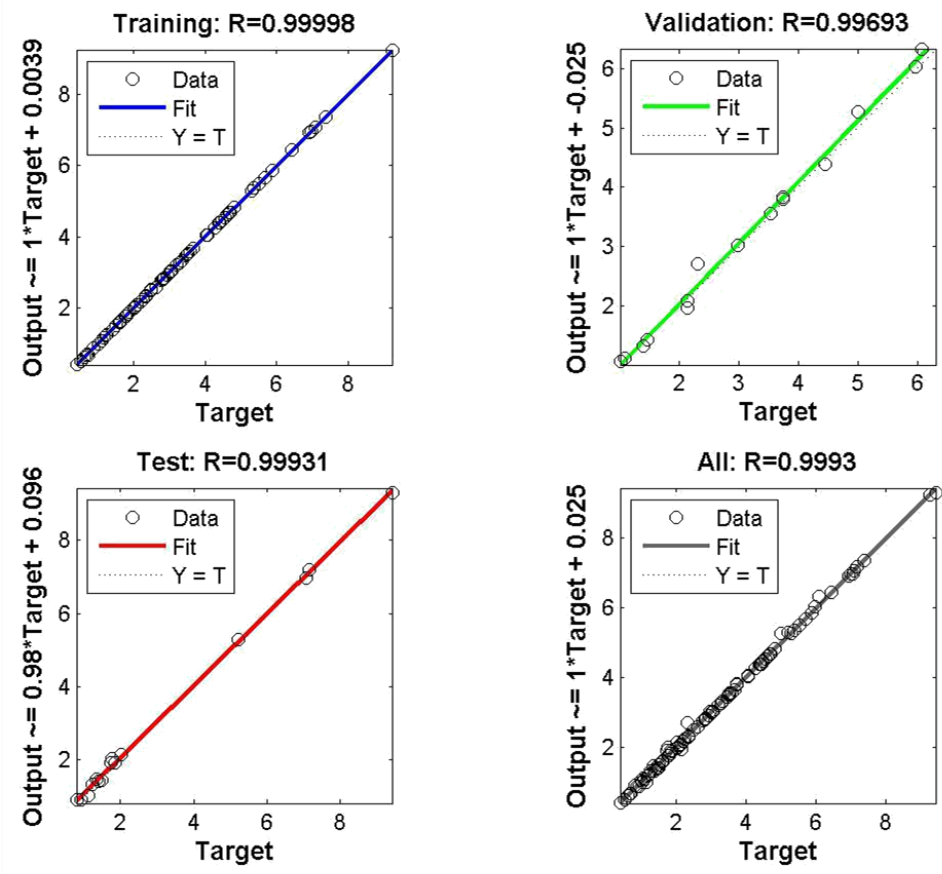

Figure 4. The regression plots of artificial neural network predictions and the numerical simulation results of elliptic cross-section for training, validation, test and combined set. 


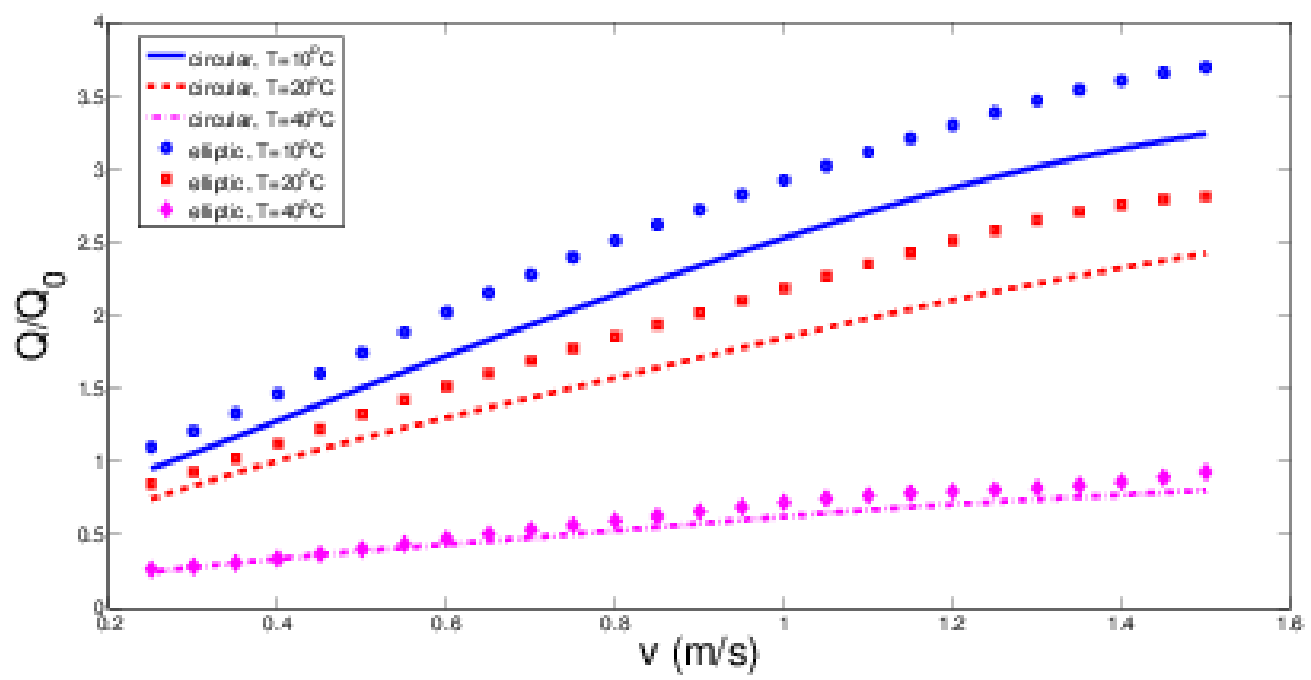

Figure 5. Effects of air velocity on the heat transfer rate from the condenser for various ambient temperatures for circular and elliptic cross-sections

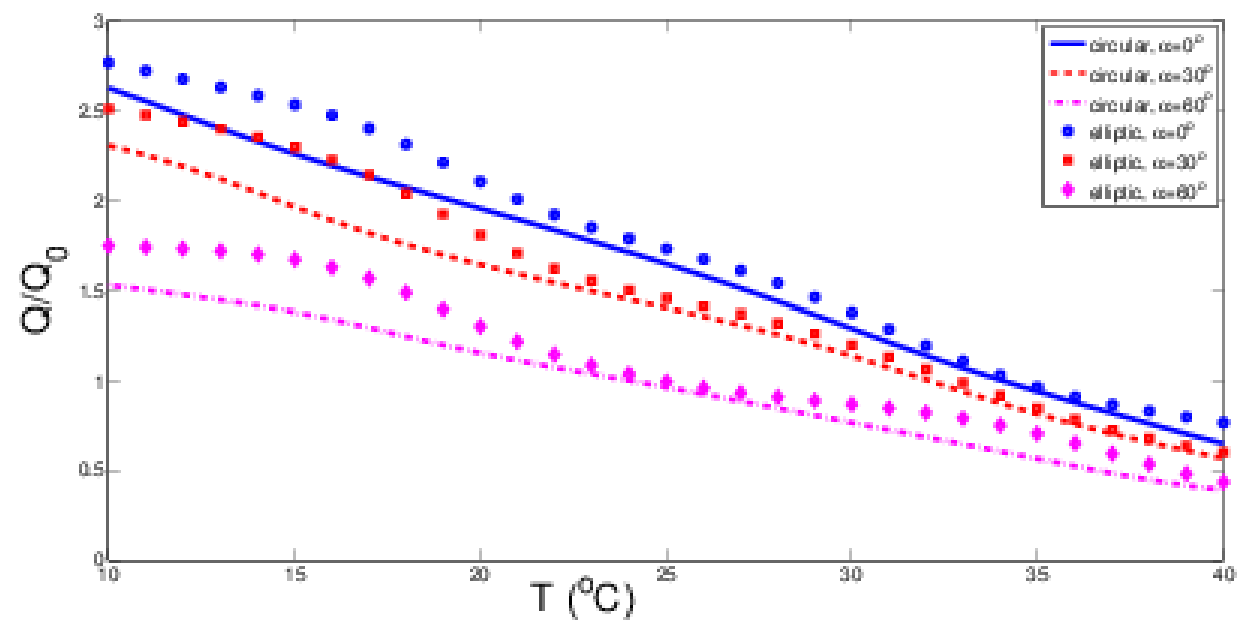

Figure 6. Effects of ambient temperature on the heat transfer rate from the condenser for various orientation angles of air velocity for circular and elliptic cross-sections

\section{CONCLUDING REMARK}

In this study, mathematical models of air cooled condensers having circular and elliptic cross-sections have been developed by using artificial neural networks. Air velocity, orientation angle and ambient temperature were the input parameters and heat transfer rate from the condenser was the output parameter to the neural network model. It was found that computationally inefficient high fidelity three dimensional computational fluid dynamics models can be replaced with effective mathematical models of artificial neural networks which are expressed in terms of weighting coefficients and input parameters. Based on the artificial neural network model, elliptic condensers were shown to have better heat transfer characteristics as compared to circular ones and the discrepancy between the heat transfer rates enhances for lower ambient temperatures and higher air velocities. Elliptic condensers perform better as compared to circular condensers especially when heat transfer rate is higher.

These cheap models of air cooled condensers with artificial neural network can be directly incorporated into a thermo-dynamic model of a refrigeration system to make further performance evaluations.

\section{ACKNOWLEDGMENTS}

This study is supported from The Scientific and Techno-logical Research Council of Turkey (TUBITAK) under the grant no: 5150047 whose support is gratefully acknowledged. 


\section{NOMECLATURE}

$\begin{array}{ll}\mathrm{g} & \text { gravitational acceleration }\left[\mathrm{m} / \mathrm{s}^{2}\right] \\ \mathrm{k} & \text { thermal conductivity }[\mathrm{W} / \mathrm{mK}] \\ \mathrm{MSE} & \text { mean square error } \\ \mathrm{n} & \text { network } \\ \mathrm{p} & \text { pressure }[\mathrm{Pa}] \\ \mathrm{Q} & \text { relative heat transfer rate }[\mathrm{W}] \\ \mathrm{R} & \text { coefficient of determination } \\ \mathrm{T} & \text { temperature }[\mathrm{K}] \\ \mathrm{u}, \mathrm{v}, \mathrm{w} & \mathrm{x}-\mathrm{y}-\mathrm{Z} \text { velocity components }[\mathrm{m} / \mathrm{s}] \\ \mathrm{x}, \mathrm{y}, \mathrm{z} & \text { Cartesian coordinates }[\mathrm{m}] \\ \alpha & \text { thermal diffusivity }\left[\mathrm{m}^{2} / \mathrm{s}\right] \\ \beta & \text { expansion coefficient }[1 / \mathrm{K}] \\ \mathrm{v} & \text { kinematic viscosity }\left[\mathrm{m}^{2} / \mathrm{s}\right] \\ \rho & \text { density of the fluid }\left[\mathrm{kg} / \mathrm{m}^{3}\right] \\ \mathrm{ANN} & \text { Artificial neural nets } \\ \mathrm{c} & \text { cold } \\ \mathrm{h} & \text { hot } \\ \mathrm{o} & \text { ambient }\end{array}$

\section{REFERENCES}

[1] Liu, P., Duan, H., Zhao, W. (2009).Numerical investigation of hot air recirculation of air-cooled condensers at a large power plant. Applied Thermal Engineering, 29,1927-1934.

[2] Sun, L., Yang, L., Shao, L.L.,Zhang, C.L. (2015). Overall thermal performance oriented numerical comparison between elliptical and circular finned-tube condensers. International Journal of Thermal Sciences, 89, $234-244$.

[3] Shabanian, S., Rahimi, M., Shahhosseini, M., Alsairafi, A. (2011). Cfd and experimental studies on heat transfer enhancement in an air cooler equipped with different tube inserts. International Communications in Heat and Mass Transfer,38, 383-390.

[4] Zhang, Z., Yang, J., Wang, Y. (2015). A favorable face velocity distribution and a v-frame cell for power plant air-cooled condensers. Applied Thermal Engineering, 87, 1-9.

[5] Li, X.D., Yang, L., Xu, Y., Yang, Y. (2013). Numerical simulation on flow and heat transfer of fin structure in air-cooled heat exchanger. Applied Thermal Engineering, 59, 77-86.

[6] Melo, C. Hermes, C.J. (2009). A heat transfer correlation for natural draft wire-and-tube condensers. International Journal of Refrigeration, 32, 546-555.

[7] Tagliafico, L., Tanda, G. (1997). Radiation and natural convection heat transfer from wire-and-tube heat exchangers in refrigeration appliances. International Journal of Refrigeration, 20, 461-469.

[8] Gupta, J., Gopal, M.R. (2008). Modeling of hot-wall condensers for domestic refrigerators. International Journal of Refrigeration, 31, 979-988.

[9] Bansal, P., Chin, T. (2003). Modelling and optimisation of wire and tube condenser. International Journal of Refrigeration, 26,601-613.

[10] Mohammed, H., Abbas, A. K., Sheriff, J. (2013). Influence of geometrical parameters and forced convective heat transfer in transversely corrugated circular tubes. International Communications in Heat and Mass Transfer, 44, 116-126.

[11] Hussain, S. H., Hussein, A. K., Mohammed, R. N. (2012). Studying the effects of a longitudinal magnetic field and discrete isoflux heat source size on natural convection inside a tilted sinusoidal corrugated enclosure. Computers and Mathematics with Applications, 64, 476-488.

[12] Nasrin, R., Alim, M., Chamkha, A. J. (2012). Combined convection flow in triangular wavy chamber filled with water-cuo nanofluid: Effect of viscosity models. International Communications in Heat and Mass Transfer, $39,1226-1236$.

[13] Selimefendigil, F., Oztop, H. F. (2016). Numerical study of forced convection of nanofluid flow over a backward facing step with a corrugated bottom wall in the presence of different shaped obstacles. Heat Transfer Engineering, 37, 1280-1292.

[14] Selimefendigil, F., Chamkha, A. J. (2016). Magnetohydrodynamics mixed convection in a lid-driven cavity having a corrugated bottom wall and filled with a non-newtonian power-law fluid under the influence of an inclined magnetic field. J. Thermal Sci. Eng. Appl., 8, 021023.

[15] Ibrahim, E., Moawed, M. (2009). Forced convection and entropy generation from elliptic tubes with longitudinal fins. Energy Conversion and Management, 50, 1946-1954.

[16] Elsayed, A.O, Ibrahim, E. Z., Elsayed, S. A. (2003). Free convection from a constant heat flux elliptic tube. Energy Conversion and Management, 44, 2445-2453. 
[17] Selimefendigil, F., Oztop, H. F. (2014). Estimation of mixed convection heat transfer of rotating cylinder in a vented cavity subjected to nanofluid by using generalized neural networks. Numerical Heat Transfer, Part A, 65, $165-185$.

[18] Aminossadati, S., Kargar, A., Ghasemi, B. (2012). Adaptive network based fuzzy inference system analysis of mixed convection in a two sided lid-driven cavity filled with a nanofluid. International Journal of Thermal Sciences, 52, 102-111.

[19] Selimefendigil, F., Oztop, H. F. (2013). Identification of forced convection in pulsating flow at a backward facing step with a stationary cylinder subjected to nanofluid. International Communications in Heat and Mass Transfer, 45, 111-121.

[20] Liang, J., Du, R. (2007). Model-based fault detection and diagnosis of hvac systems using support vector machine method. International Journal of Refrigeration, 30, 1104-1114.

[21] Selimefendigil, F., Oztop, H. F. (2012). Fuzzy-based estimation of mixed convection heat transfer in a square cavity in the presence of an adiabatic inclined fin. International Communications in Heat and Mass Transfer, 39 , 1639-1646.

[22] Varol, Y., Oztop, H. F., Avci, E. (2008). Estimation of thermal and flow fields due to natural convection using support vector machines (svm) in a porous cavity with discrete heat sources. International Communications in Heat and Mass Transfer, 35, 928-936.

[23] Kalogirou, S. (1999). Applications of artificial neural networks in energy systems a review. Energy Conversion and Management, 40, 1073-1087.

[24] Sahin, A. S. (2011). Performance analysis of single-stage refrigeration system with internal heat exchanger using neural network and neuro-fuzzy. Renewable Energy, 36, 2747-2752.

[25] Ertunc, H. M., Hosoz, M. (2008). Comparative analysis of an evaporative condenser using artificial neural network and adaptive neuro-fuzzy inference system. International Journal of Refrigeration, 31, 1426-1436.

[26] Markatos, N. (1989). Computational fluid flow capabilities and software. Ironmaking Steelmaking, 16, 266273.

[27] Versteeg, H., Malalasekera, W. (1999). An Introduction to Computational Fluid Dynamics: The Finite Volume Method. Harlow: Addison- Wesley, Longman Limited.

[28] Pha, D.T. (1995). Neural Networks for Identification, Prediction and Control. Springer.

[29] Juditsky, A., Hjalmarsson, H., Beneviste, A., Delyon, B., Ljung, L., Sjoberg, J., Zhang, Q. (1995). Nonlinear black-box models in system identification: mathematical foundations. Automatica, 31, 1725-1750. 